\title{
ATLAS AWARD FOR \\ INTERNATIONAL JOURNAL OF EPILEPSY (IJEP) - JUNE 2015
}

International Journal of Epilepsy is happy to convey that article by Ranganathan LN, Chinnadurai SA, Samivel B, Kesavamurthy B, Mehndiratta MM.1 was awarded "The Atlas" for the month of June 2015 (fig. 1) which was selected from 225,000 articles published in June 2015.

\section{About Atlas - Research for a better world}

Science impacts everyone's world. With over 2,500 journals publishing articles from across science, technology and health, our mission is to share some of the stories that matter. Each month Atlas showcases research that could significantly impact people's lives around the world or has already done so. We hope that bringing wider attention to this research will go some way to ensuring its successful implementation.

With so many worthy articles published the tough job of selecting a single article to be awarded "The Atlas" each month comes down to an Advisory Board. The winning research is presented alongside interviews, expert opinions, multimedia and much more on the Atlas website.

We aim to showcase some of the articles that can make a real difference and hope you'll find this to be a valuable resource.

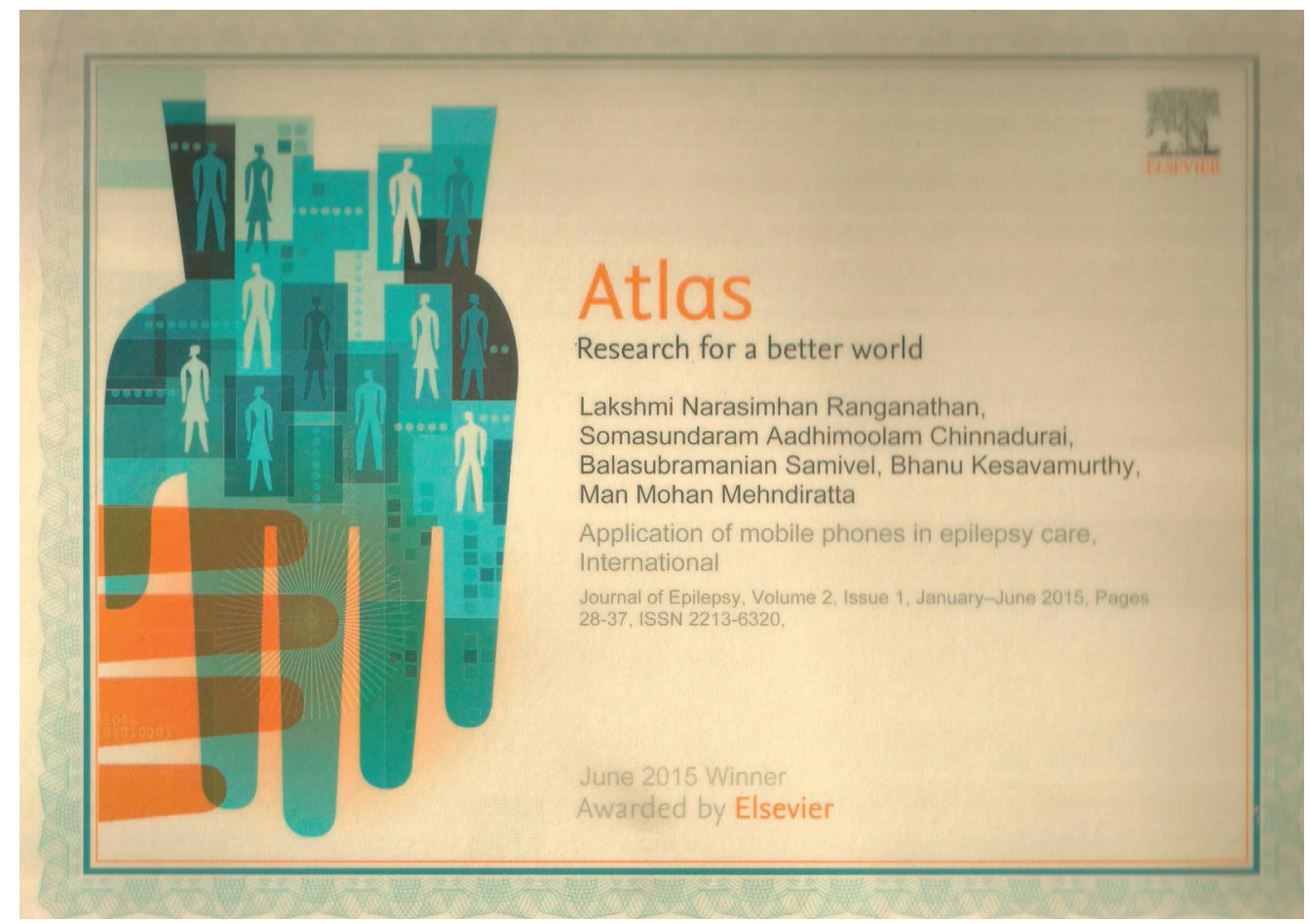

Figure 1: Certificate awarded to authors of the article

Reference:

1. Ranganathan LN, Chinnadurai SA, Samivel B, Kesavamurthy B, Mehndiratta MM. Application of mobile phones in epilepsy care. International Journal of Epilepsy, 2015; $2: 28-37$ 